Journal of Industrial and Engineering System (JIES)

e-ISSN: 2722-7979

Vol. 2 No. 1, Hal 13-20

\title{
Analisis Safety Performance Index dengan Pendekatan Behavior-Based Safety pada Industri Manufaktur Komponen Otomotif Yayan Saputra* ${ }^{1}$, Murwan Widyantoro ${ }^{2}$, Fibi Eko Putra ${ }^{3}$, Putri Nika Andini ${ }^{4}$ \\ ${ }^{1,2}$ Teknik Industri Fakultas Teknik, Universitas Bhayangkara Jakarta \\ ${ }^{3}$ Teknik Industri, Fakultas Teknik, Universitas Pelita Bangsa, Jawa Barat, Indonesia \\ ${ }^{4}$ Teknik Lingkungan, Fakultas Teknik, Universitas Pelita Bangsa, Jawa Barat, Indonesia e-mail: *1-yayan.saputra@dsn.ubharajaya.ac.id, ${ }^{-}$murwan@dsn.ubharajaya.ac.id, \\ ${ }^{3}$ fibiekoputra@gmail.com, ${ }^{4}$ putrinikaandini@gmail.com \\ * Korespondensi: yayan.saputra@dsn.ubharajaya.ac.id
}

\begin{abstract}
Occupational health and safety is one of the necessary things in the industrial world. Health conditions and the availability of employee safety protections can affect work productivity. safety culture in the workplace can be realized and can increase the safety performance index, an approach was implemented form of methods that can be applied to all organizations, one of which is behaviorbased safety methods. The analysis of data obtained shows the factors cause work accidents due to behavior are taken from the validity of perception, communication and environment because these three factors are very easily ignored by employees and company management. Environmental factors and personal protective equipment have no effect on work accidents as always provides periodic education to its employees and enforces strict rules on the use of personal protective equipment. The magnitude of the influence of the variables studied in Behavior-Based safety in an effort to improve safe condition was $79.7 \%$ and the remaining $20.3 \%$ was influenced by other unexamined items. The value of $79.7 \%$ consists of perception, communication and environment.
\end{abstract}

Keywords : Behavior Based Safety, Perception, Communication, Environment

\begin{abstract}
ABSTRAK
Kesehatan dan keselamatan kerja merupakan salah satu hal yang diperlukan dalam dunia industri. Kondisi kesehatan dan ketersediaan perlindungan keselamatan kerja dapat mempengaruhi produktivitas kerja. Agar budaya keselamatan dan keamanan dalam bekerja di tempat kerja dapat terwujud dan dapat meningkatkan indeks kinerja keselamatan, pendekatan tersebut diimplementasikan dalam bentuk metode yang dapat diterapkan pada semua perusahaan, salah satunya adalah behavior based safety Analisis data yang diperoleh menunjukkan bahwa faktor penyebab kecelakaan kerja akibat perilaku diambil dari uji validitas yaitu faktor persepsi, komunikasi dan lingkungan, karena ketiga faktor tersebut sangat mudah diabaikan oleh karyawan dan manajemen perusahaan. Faktor lingkungan dan alat pelindung diri tidak mempengaruhi terjadinya kecelakaan kerja karena pihak manajemen selalu memberikan edukasi secara berkala kepada setiap karyawan dan memberlakukan aturan yang tegas terhadap penggunaan alat pelindung diri. Besarnya pengaruh variabel yang diteliti dalam perilaku keselamatan berbasis dalam upaya perbaikan kondisi aman adalah 79,7\% dan sisanya 20,3\% dipengaruhi oleh item lain yang tidak diteliti. Nilai 79,7\% terdiri dari persepsi, komunikasi dan lingkungan.
\end{abstract}

Kata Kunci: Behaviour Based Safety, Kesehatan dan keselamatan kerja, kecelakaan kerja, kondisi aman, persepsi, komunikasi, lingkungan

\section{PENDAHULUAN}

Kesehatan dan keselamatan kerja merupakan salah satu hal yang sangat dibutuhkan dalam dunia industri. Persoalan yang muncul di era industrialisasi adalah kebutuhan pekerja dan peningkatan produktivitas untuk dapat menghasilkan produk yang berkualitas. Data BPJS Ketenagakerjaan menyebutkan kasus kecelakaan kerja cenderung meningkat dari 
tahun ke tahun, dimana sepanjang tahun 2018 terjadi 173.105, naik 40,6\% dari tahun 2017 (bpjsketenagakerjaan.go.id,2019).

Keselamatan kerja menunjukkan pada kondisi yang aman atau selamat dari penderitaan, kerusakan atau kerugian di tempat (Mangkunegara, 2000). Keselamatan kerja adalah keselamatan yang bertalian dengan mesin, alat kerja, proses pengolahannya, landasan tempat kerja dan lingkungan serta cara-cara melakukan pekerjaan (P.K., 1993). Keselamatan mencakup istilah risiko keselamatan dan risiko kesehatan (Mangkunegara, 1993). Program kesehatan kerja menunjukkan pada kondisi yang bebas dari gangguan fisik, mental, emosi atau rasa sakit yang disebabkan oleh lingkungan (Mangkunegara, 2000). Risiko kesehatan merupakan faktor-faktor dalam lingkungan kerja yang bekerja melebihi periode waktu yang ditentukan. Lingkungan dapat membuat tekanan emosi atau gangguan fisik.

Kesehatan kerja diartikan sebagai ilmu kesehatan dan penerapannya yang bertujuan mewujudkan tenaga kerja sehat, produktif dalam bekerja, berada dalam keseimbangan yang mantap antara kapasitas kerja, beban kerja dan keadaan lingkungan kerja, serta terlindungi dari penyakit yang disebabkan oleh pekerjaan dan lingkungan kerja (P.K., 1996). Kondisi kesehatan dan tersedianya perlindungan keselamatan pekerja dapat mempengaruhi produktivitas kerja. Angka kejadian kecelakaan kerja dengan berbagai ancaman di bidang Keselamatan dan Kesehatan Kerja di Indonesia masih cukup tinggi. Agar Pembudayaan Kesehatan dan Keselamatan Kerja di tempat kerja dapat terwujud dan dapat meningkatkan safety performance index, maka salah satu cara yang diterapkan berupa metode yang mampu diaplikasikan kepada semua organisasi yang ada di perusahaan, yaitu salah satunya adalah metode behavior based safety.

Behavior-Based Safety merupakan sebuah proses yang menciptakan kemitraan keamanan yang dilakukan antara manajemen dan pekerja dengan fokus yang berkelanjutan terhadap perhatian dan tindakan terhadap setiap orang dan orang lain, serta upaya untuk berperilaku selamat (Cooper, 2009). Perilaku aman dapat dilihat dari perilaku pekerja ketika melakukan pekerjaannya di tempat kerja. Dari riset yang dilakukan oleh banyak ahli behavior di banyak negara memperlihatkan bahwa penerapan teknik-teknik behavioral safety dapat mengurangi kecelakaan antara 40-75\% dalam waktu dua sampai enam belas bulan (Geller, 2001). Oleh karena itu, BehaviorBased Safety merupakan pendekatan yang komprehensif apabila diterapkan dalam Sistem Manajemen Keselamatan dan Kesehatan Kerja (Krause, 2000).

Insiden pekerjaan masih merupakan persentase kematian dan cacat yang tinggi (Goh et al., 2012). Kecelakaan terjadi karena berbagai sebab, sebagian besar kecelakaan terjadi akibat kombinasi dari penyebab yang berkontribusi dalam satu atau lebih tindakan yang tidak aman dan kondisi tidak aman(Abdul Rahim et al., 2008). Tidak semua budaya keselamatan yang disepakati mampu mendefinisikan atau menjelaskan tentang budaya keselamatan dalam suatu organisasi (Nielsen, 2014). Kinerja keselamatan ditinjau dari sejauh mana perusahaan dapat mencegah terjadinya kecelakaan dan kesalahan kerja (De Koster et al., 2011).

Dalam penelitian ini memiliki tujuan untuk menentukan faktor persepsi, komunikasi, dan lingkungan terhadap kesehatan dan keselamatan kerja dengan pengaruh kondisi aman saat bekerja.

\section{METODE PENELITIAN}

Salah satu kegiatan dalam penerapan sistem manajemen keselamatan dan kesehatan kerja baik OHSAS 18001:2007 ataupun SMK3 PP 50/2012 adalah melakukan pengukuran kinerja K3. Pengukuran dapat dilakukan dengan metode statistik yang bertujuan untuk:

1. Mengidentifikasi naik turunnya (trend) dari timbulnya kecelakaan kerja.

2. Mengetahui peningkatan atau berbagai hal yang memperburuk kinerja $\mathrm{K} 3$

3. Membandingkan kinerja antara tempat kerja dan industri yang serupa $(T-$ Safe Score).

4. Memberikan informasi mengenai prioritas pengalokasian dana $\mathrm{K} 3$. 
5. Memonitor kinerja organisasi, khususnya mengenai persyaratan untuk penyediaan sistim/tempat kerja yang aman

Berdasarkan Peraturan Menteri Tenaga

Kerja No.03/MEN/1998 tentang Tata Cara

Pelaporan dan Pemeriksaan Kecelakaan terdapat standar perhitungan Statistik Angka Kecelakaan Kerja sebagai berikut:

1. Frequency Rate (FR) adalah banyaknya kecelakaan kerja per satu juta jam kerja orang akibat kecelakaan selama periode 1 tahun.

2. Severity Rate (SR) adalah angka yang menunjukan jumlah hari yang hilang per satu juta jam kerja orang akibat kecelakaan selama periode 1 tahun.

3. Incidence Rate adalah perbandingan antara suatu kejadian dengan jumlah populasi yang mempunyai risiko kejadian tersebut, menyangkut interval waktu tertentu.

Pandangan dari Kesehatan dan Keselamatan Kerja tentang tingkat pengetahuan, pemahaman, dan tingkat praktis mencerminkan lingkungan kerja mereka (Osman et al., 2013). Oleh karena itu, penting untuk meningkatkan tingkat pengetahuan dan tingkat pemahaman di antara karyawan untuk memastikan bahwa pekerja dapat menggunakan cara mereka dalam perilaku kerja yang aman.

Kecenderungan orang melakukan perilaku tidak aman dalam melakukan pekerjaan, disebabkan oleh beberapa aspek, yaitu karena ingin menyelesaikan pekerjaan secara cepat, tidak ada pengawasan, terdapat permintaan dari atasan untuk menyelesaikan pekerjaan secara cepat, kepercayaan diri yang berlebihan karena sudah banyak pengalaman dan tidak pernah mengalami kecelakaan sebelumnya, dan Sedang dalam kondisi psikologis yang tertekan karena masalah keluarga, terlalu lelah karena kerja lembur, dan sebagainya.

Behavior-Based Safety adalah proses pendekatan untuk meningkatkan keselamatan kesehatan kerja dan lingkungan dengan jalan menolong sekelompok pekerja untuk mengidentifikasi perilaku yang berkaitan dengan keselamatan dan kesehatan kerja, mengumpulkan data kelompok pekerja, memberikan feedback dua arah mengenai perilaku keselamatan dan kesehatan kerja, dan mengurangi atau meniadakan hambatan sistem untuk perkembangan lebih lanjut.

Implementasi atas intervensi Behavior Based Safety adalah latihan utama dan melibatkan penerapan prinsip perubahan penting (Osman et al., 2013). Fitur utama dari implementasi Behavior Based Safety adalah komitmen, fokus, tujuan, dan eksekusi. Konsep pendekatan Behavior-Based Safety mengacu pada aplikasi sistematis penelitian psikologis pada perilaku manusia yang bertujuan mengubah perilaku yang tidak aman menjadi aman. Behavior-Based Safety dapat digunakan dalam melengkapi perusahaan untuk mengubah perilaku dan sikap karyawan terhadap keselamatan (Kaczmarek et al., 2015). Contoh panduan untuk implementasi Behavior-Based Safety di perusahaan berdasarkan survei literatur disajikan pada tabel 1 (Kaczmarek et al., 2015). 
Yayan Saputra, Murwan Widyantoro, Fibi Eko Putra, Putri Nika Andini

Submitted: 08/02/2021; Revised: 31/03/2021; Accepted: 10/06/2021; Published: 30/06/2021

Tabel 1. Panduan implementasi Behaviour based safety

\begin{tabular}{cll}
\hline Langkah & \multicolumn{1}{c}{ Deskripsi } & \multicolumn{1}{c}{ Karakteristik } \\
\hline 1 & $\begin{array}{l}\text { Tunjukkan konsep BBS kepada } \\
\text { manajemen perusahaan dan dapatkan } \\
\text { komitmen dari mereka. Kemudian } \\
\text { bentuk tim Pengarah BBS }\end{array}$ & $\begin{array}{l}\text { Setiap perusahan harus menyesuaikan pedoman } \\
\text { sesuai dengan visi dan misi perusahaan karena } \\
\text { keberhasilan BBS tergantung pada kualitas sistem } \\
\text { manajemen, kepemimpinan, komitmen, dan }\end{array}$ \\
& budaya perusahaan terhadap lingkungan, \\
& kesehatan, dan keselamatan
\end{tabular}

Metode penelitian yang digunakan dalam penelitian ini adalah melakukan penyebaran kuesioner terhadap para pekerja di bagian finishing \& injection yang berjumlah 94 orang. Untuk mendapatkan sampel dari populasi tersebut, maka digunakan rumus slovin untuk penentuan sampel yang kemudian sampel tersebut ditarik secara acak menggunakan dengan simple random sampling.

$n=\frac{N}{1+N_{i}^{2}}$

Data yang dibutuhkan dalam penelitian ini adalah data primer yang didapat dengan observasi lapangan dan data sekunder yang didapat dari manajemen Health, Safety, and 
Environment (HSE) pada salah satu industri komponen otomotif dengan objek dalam penelitian ini adalah karyawan yang bekerja pada bagian finishing \& injection yang berjumlah 76 orang dari 94 karyawan.

\section{HASIL DAN PEMBAHASAN}

Validitas adalah suatu ukuran yang menunjukkan tingkat-tingkat kevalidan atau kesahihan suatu instrument dengan responden dan hasil validitas sebagai berikut:

Tabel 2. Responden berdasarkan jenis kelamin

\begin{tabular}{cccc}
\hline & Jenis Kelamin & Frequency & Percent \\
\hline Valid & Laki-laki & 74 & $76,29 \%$ \\
& Perempuan & 23 & $23,71 \%$ \\
& TOTAL & $\mathbf{9 7}$ & $\mathbf{1 0 0 , 0 0 \%}$ \\
\hline
\end{tabular}

Tabel 3. Responden berdasarkan umur

\begin{tabular}{cccc}
\hline & Umur & Frequency & Percent \\
\hline Valid & $20-25$ & 36 & $37,11 \%$ \\
& $25-30$ & 22 & $22,68 \%$ \\
& $30-35$ & 25 & $25,77 \%$ \\
& $35-40$ & 14 & $14,43 \%$ \\
\multicolumn{2}{c}{ TOTAL } & $\mathbf{9 7}$ & $\mathbf{1 0 0 , 0 0 \%}$ \\
\hline
\end{tabular}

Tabel 4. Responden berdasarkan pendidikan

\begin{tabular}{cccc}
\hline Pendidikan & Frequency & Percent \\
\hline Valid & SMA/SMK & 64 & $65,98 \%$ \\
& D3 & 23 & $23,71 \%$ \\
S1 & 10 & $10,31 \%$ \\
TOTAL & $\mathbf{9 7}$ & $\mathbf{1 0 0 , 0 0 \%}$ \\
\hline
\end{tabular}

Tabel 5. Uji Validitas

\begin{tabular}{|c|c|c|c|c|c|c|c|}
\hline & & Knowledge & Perception & Communication & Environment & $\begin{array}{l}\text { Personal } \\
\text { Protective } \\
\text { Equipment }\end{array}$ & $\begin{array}{c}\text { Safe } \\
\text { Work } \\
\text { Behavior }\end{array}$ \\
\hline \multirow[t]{4}{*}{ Knowledge } & Pearson & & & & & & \\
\hline & Correlation & 1 & $-0,164$ & $-0,007$ & $-0,127$ & $0,993^{*}$ & 0,103 \\
\hline & Sig (2 tailed) & & 0,157 & 0,945 & 0,275 & 0 & 0,376 \\
\hline & $\mathrm{N}$ & 76 & 76 & 76 & 76 & 76 & 76 \\
\hline \multirow[t]{3}{*}{ Perception } & Pearson & -0164 & 1 & $0651 *$ & 0012 & -017 & $0777 *$ \\
\hline & Sig (2 tailed) & 0,157 & & 0 & 0,921 & 0,142 & 0 \\
\hline & $\mathrm{N}$ & 76 & 76 & 76 & 76 & 76 & 76 \\
\hline \multirow[t]{4}{*}{ Communication } & Pearson & & $0651^{*}$ & 1 & 0103 & 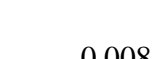 & $0800 *$ \\
\hline & Correlation & $-0,008$ & $0,651^{*}$ & 1 & 0,193 & $-0,008$ & 0,002 \\
\hline & Sig (2 tailed) & 0,945 & 0 & & 0,095 & 0,943 & 0 \\
\hline & $\mathrm{N}$ & 76 & 76 & 76 & 76 & 76 & 76 \\
\hline \multirow[t]{4}{*}{ Environment } & Pearson & & & & & & \\
\hline & Correlation & $-0,127$ & 0,012 & 0,193 & 1 & $-0,138$ & $0,299^{*}$ \\
\hline & Sig (2 tailed) & 0,275 & 0,921 & 0,095 & & 0,236 & 0,009 \\
\hline & $\mathrm{N}$ & 76 & 76 & 76 & 76 & 76 & 76 \\
\hline \multirow[t]{3}{*}{$\begin{array}{l}\text { Personal } \\
\text { Protective } \\
\text { Equipment }\end{array}$} & $\begin{array}{l}\text { Pearson } \\
\text { Correlation }\end{array}$ & $0,993 *$ & $-0,17$ & $-0,008$ & $-0,138$ & 1 & 0,102 \\
\hline & Sig (2 tailed) & & & & & & \\
\hline & $\mathrm{N}$ & 76 & 76 & 76 & 76 & 76 & 76 \\
\hline \multirow[t]{3}{*}{$\begin{array}{l}\text { Safe Work } \\
\text { Behavior }\end{array}$} & $\begin{array}{l}\text { Pearson } \\
\text { Correlation }\end{array}$ & 0,103 & $0,777^{*}$ & $0,802 *$ & $0,299^{*}$ & 0,102 & 1 \\
\hline & Sig (2 tailed) & 0,376 & 0 & 0 & 0,009 & 0,382 & \\
\hline & $\mathrm{N}$ & 76 & 76 & 76 & 76 & 76 & 76 \\
\hline
\end{tabular}

* correlation is significant at the 0,01 level (2-tailed) 
Dari hasil tersebut dapat diambil bahwa variabel pengetahuan dan APD tidak valid karena nilai validitasnya rendah dibawah 0.226 . Untuk variabel persepsi, lingkungan dan komunikasi dinyatakan valid karena nilai validitasnya diatas 0.226 . Kemudian variabel yang valid tersebut dapat melanjutkan ke penelitian berikutnya.

Kriteria dari nilai Croanbach's Alpha adalah apabila didapatkan nilai Croanbach Alpha sebesar 0,545. Selanjutnya dengan menggunakan taraf signifikansi $\alpha=0,05$ nilai reliabilitas yang diperoleh dari hasil perhitungan diperbandingkan dengan nilai dari table korelasi nilai $r$ dengan derajat kebebasan.

\begin{tabular}{|c|c|c|c|c|}
\hline \multicolumn{4}{|c|}{ Tabel 6. Uji Reliabilitas } & \\
\hline & \multicolumn{2}{|c|}{ Cronbach's } & $\mathrm{N}$ of Items & \\
\hline & & .545 & 3 & \\
\hline & $\begin{array}{l}\text { Scale } \\
\text { Mean } \\
\text { if Item } \\
\text { Deleted }\end{array}$ & $\begin{array}{l}\text { Scale } \\
\text { Variance } \\
\text { if Item } \\
\text { Deleted }\end{array}$ & $\begin{array}{l}\text { Corrected } \\
\text { Item-Total } \\
\text { Correlation }\end{array}$ & $\begin{array}{l}\text { Cronbach's } \\
\text { Alpha if } \\
\text { Item } \\
\text { Deleted }\end{array}$ \\
\hline Perception & 68.42 & 8.727 & .426 & .323 \\
\hline Communication & 68.16 & 8.108 & .605 & .023 \\
\hline Environtment & 69.82 & 13.059 & .108 & .787 \\
\hline
\end{tabular}

Kesimpulan yang didapat dari penelitian tersebut, bahwa variabel persepsi, komunikasi tidak reliabel, sedangkan lingkungan reliabel. Selanjutnya dilakukan uji $\mathrm{T}$ parsial dari model

\begin{tabular}{|c|c|c|c|c|c|c|}
\hline & \multirow[t]{2}{*}{ Model } & \multicolumn{2}{|c|}{$\begin{array}{c}\text { Unstandardized } \\
\text { Coefficient }\end{array}$} & \multirow{2}{*}{$\begin{array}{c}\text { Standa } \\
\text { rdized } \\
\text { Coeffic } \\
\text { ient } \\
\text { Beta }\end{array}$} & \multirow[t]{2}{*}{$\mathrm{t}$} & \multirow[t]{2}{*}{$\begin{array}{c}\mathrm{Si} \\
\mathrm{g}\end{array}$} \\
\hline & & B & $\begin{array}{l}\text { Std. } \\
\text { Error }\end{array}$ & & & \\
\hline \multirow[t]{4}{*}{1} & (Constant) & 35,31 & 8,817 & & 4,005 & 0 \\
\hline & Perception & 1,561 & 0,229 & 0,483 & 6,814 & 0 \\
\hline & Communication & 1,582 & 0,255 & 0,448 & 6,200 & 0 \\
\hline & Environment & 0,723 & 0,191 & 0,207 & 3,784 & 0 \\
\hline
\end{tabular}

keputusan uji t parsial dalam analisis regresi dapat disimpulkan sebagai berikut:

1. Variabel Persepsi secara parsial berpengaruh signifikan terhadap perilaku kerja aman.
2. Variabel Komunikasi secara parsial berpengaruh signifikan terhadap perilaku kerja aman.

3. Variabel Lingkungan secara parsial berpengaruh signifikan terhadap perilaku kerja aman.

Dalam uji $\mathrm{F}$ simultan dilakukan dengan tingkat kepercayaan 5\% atau 0,05 dalam hal ini kita bisa uji dengan rumus tersebut. Pada $\mathrm{df}_{1}=4-1=3$. Dan pada $\mathrm{df}_{2}=76-4=72$, maka nilai $\mathrm{F}$ tabel adalah 2,73.

Tabel 8. Uji F Simultan

\begin{tabular}{llrrrrc}
\hline Model & $\begin{array}{c}\text { Sum of } \\
\text { Squares }\end{array}$ & df & $\begin{array}{c}\text { Mean } \\
\text { Square }\end{array}$ & F & Sig \\
& $\cdot$ \\
\hline Regressi & & & 89711 & 9396 & \\
on & 2691350 & 3 & 7 & 3 & $0^{\mathrm{b}}$ \\
1 & Residual & 687426 & 72 & 9548 & & \\
& Total & 3378776 & 75 & & & \\
\hline
\end{tabular}

a Dependent variable; Perilaku Kerja Aman

b Predictors: (Constant), Lingkungan, Persepsi, Komunikasi

Dalam uji F, F Hitung lebih besar dari F tabel, yaitu nilai $\mathrm{F}$ hitung adalah 93.963. Sedangkan nilai $\mathrm{F}$ tabel sebesar 2.73 yang berarti nilai $\mathrm{F}$ hitung lebih besar dari $\mathrm{F}$ tabel maka dapat disimpulkan bahwa terdapat pengaruh yang signifikan antara Persepsi (X2), Komunikasi (X3) dan Lingkungan (X4) secara simultan terhadap perilaku kerja aman (Y).

$Y=X_{2}+X_{3}+X_{4}$

Nilai Sig. lebih kecil dari taraf signifikansi yang digunakan, yaitu 0,05, maka terdapat pengaruh yang signifikan antara Persepsi, Komunikasi, dan Lingkungan secara simultan terhadap perilaku kerja aman.

Nilai koefisien determinasi adalah antara 0 dan 1. Bila $\mathrm{R}$ diantara 0 berarti diantara variabel bebas dengan variabel terikat tidak ada hubungannya, sedangkan bila $\mathrm{R}=1$ berarti antara variabel bebas dengan variabel terikat mempunyai hubungan. Nilai koefisien determinasi $\left(\mathrm{R}^{2}\right)$ ini mencerminkan seberapa besar variasi dari variabel terikat $(\mathrm{Y})$ dapat diterangkan oleh variabel bebas. 
Yayan Saputra, Murwan Widyantoro, Fibi Eko Putra, Putri Nika Andini

Submitted: 08/02/2021; Revised: 31/03/2021; Accepted: 10/06/2021; Published: 30/06/2021

Tabel 9. Uji Koefisien Determinasi

\begin{tabular}{|c|c|c|c|c|}
\hline \multicolumn{5}{|c|}{ Model Summary } \\
\hline $\begin{array}{c}\text { Mode } \\
1\end{array}$ & $\mathrm{R}$ & $\begin{array}{c}\mathrm{R} \\
\text { Square }\end{array}$ & $\begin{array}{l}\text { Adjusted } \\
\text { R Squre }\end{array}$ & $\begin{array}{l}\text { Std Error } \\
\text { of the } \\
\text { Estimate }\end{array}$ \\
\hline
\end{tabular}

a. Predictors: (Constant), Lingkungan, Persepsi,

Komunikasi

Dari tabel 9 maka dapat diketahui nilai $\mathrm{R}^{2}$ sebesar 0,797. Dari nilai tersebut dapat dilihat bahwa perilaku kerja aman dipengaruhi oleh persepsi, komunikasi dan lingkungan sebesar 0,797. Hal ini berarti perilaku kerja aman dipengaruhi oleh persepsi, komunikasi dan lingkungan sebesar $79,7 \%$ dan sisanya sebesar 20,3\% dipengaruhi oleh hal-hal lain yang tidak diteliti.

\section{KESIMPULAN}

Dari analisa data yang telah dilakukan diperoleh kesimpulan bahwa faktor yang menyebabkan terjadinya kecelakaan kerja disebabkan oleh perilaku diambil dari uji validitas, yaitu faktor persepsi, komunikasi dan lingkungan, karena ketiga faktor tersebut sangat rentan diabaikan oleh karyawan maupun manajemen perusahaan. Faktor lingkungan dan Alat Pelindung Diri tidak berpengaruh terhadap kecelakaan kerja karena pihak manajemen selalu memberikan edukasi berkala kepada karyawannya dan menegakkan peraturan yang ketat dalam penggunaan Alat Pelindung Diri. Besarnya pengaruh variabel yang diteliti dalam Behavior-Based Safety dalam upaya peningkatan Safe behavior yaitu sebesar $79,7 \%$ dan sisanya sebesar 20,3\% dipengaruhi oleh hal-hal lain yang tidak diteliti. Nilai $79,7 \%$ tersebut terdiri dari persepsi, komunikasi dan lingkungan.

Untuk penelitian selanjutnya diharapkan untuk membahas faktor lain yang mempengaruhi kondisi aman dalam bekerja untuk meningkatkan kesadaran dalam keselamatan dan kesehatan kerja selain faktor persepsi, komunikasi, dan lingkungan.

\section{DAFTAR PUSTAKA}

Abdul Rahim, A. H., Muhd Zaimi, A. M., \& Bachan, S. (2008). Cause of Accident at Construction Sites. Malaysian Journal of Civil Engineering, 20(2), 242-259.

bpjsketenagakerjaan.go.id. (2019). Angka Kecelakaan Kerja Cenderung Meningkat,
BPJS Ketenagakerjaan Bayar Santunan Rpl,2 Triliun. Bpjsketenagakerjaan.Go.Id. Diakses pada 23 Maret 2021, https://www.bpjsketenagakerjaan.go.id/b erita/23322/Angka-Kecelakaan-KerjaCender

Cooper, D. (2009). Behavioral Safety a Framework for Success. BSMS.

De Koster, R. B. M., Stam, D., \& Balk, B. M. (2011). Accidents happen: The influence of safety-specific transformational leadership, safety consciousness, and hazard reducing systems on warehouse accidents. Journal of Operations Management, 29(7-8), 753-765. https://doi.org/10.1016/j.jom.2011.06.005

Geller, E. S. (2001). The Psychology of Safety Handbook. Lewis Publisher.

Goh, Y. M., Love, P. E. D., Stagbouer, G., \& Annesley, C. (2012). Dynamics of safety performance and culture: A group model building approach. Accident Analysis and Prevention, $\quad 48, \quad 118-125$. https://doi.org/10.1016/j.aap.2011.05.010

Kaczmarek, L. D., Kashdan, T. B., Drazkowski, D., Enko, J., Kosakowski, M., Szäefer, A., \& Bujacz, A. (2015). Why do people prefer gratitude journaling over gratitude letters? The influence of individual differences in motivation and personality on web-based interventions. Personality and Individual Differences, $\quad 75, \quad 1-6$. https://doi.org/10.1016/j.paid.2014.11.00 4

Krause, T. R. (2000). The Behavior-Based Safety Process: 2nd Edition. Willey Publisher.

Mangkunegara, A. P. (1993). Psikologi Perusahaan. Triguna Karya.

Mangkunegara, A. P. (2000). Manajemen Sumber Daya Manusia Perusahaan Cetakan Kedua. Remaja Rosda Karya.

Nielsen, K. J. (2014). Improving safety culture through the health and safety organization: A case study. Journal of Safety Research, 48, 7-17. https://doi.org/10.1016/j.jsr.2013.10.003

Osman, I. H., Anouze, A. L., \& Emrouznejad, A. (2013). Handbook of research on strategic performance management and 
Yayan Saputra, Murwan Widyantoro, Fibi Eko Putra, Putri Nika Andini

Submitted: 08/02/2021; Revised: 31/03/2021; Accepted: 10/06/2021; Published: 30/06/2021

measurement using data envelopment analysis. Handbook of Research on Strategic Performance Management and Measurement Using Data Envelopment Analysis, November, 1-735. https://doi.org/10.4018/978-1-4666-44748
P.K., S. (1993). Keselamatan Kerja dan Pencegahan Kecelakaan. Gunung Agung.

P.K., S. (1996). Higene Perusahaan dan Kesehatan Kerja. Gunung Agung. 